\section{Is this really pneumothorax?}

A 75-year-old female non-smoker was admitted for investigation of suspected interstitial lung disease. A left lower lobe transbronchial lung biopsy was performed, complicated by suspected bilateral pneumothoraces, pneumomediastinum and surgical emphysema (fig 1). Bilateral intercostal catheters (ICCs) were inserted. In view of the ongoing air leak and worsening surgical emphysema, a CT chest was undertaken. This was suspicious of extrapleural air leak. Following cardiothoracic consultation, video assisted thoracic surgery was performed which confirmed obliterated pleural spaces bilaterally with extrapleural air leak, as shown in fig 2 . Bilateral ICCs were inserted into the air filled extrapleural space with dramatic reduction in surgical emphysema. The patient declined further invasive investigations.

\section{P Singh, J Armstrong, M A Murphy, J Coucher, B Ong}

QE II Jubilee Hospital, Brisbane, Australia

Correspondence to: M P Singh, QE II Jubilee Hospital, Cnr Kessels and Troughton Roads, Coopers Plains, Brisbane, OLD 4108, Australia; maninder.singh@health.qld.gov.au

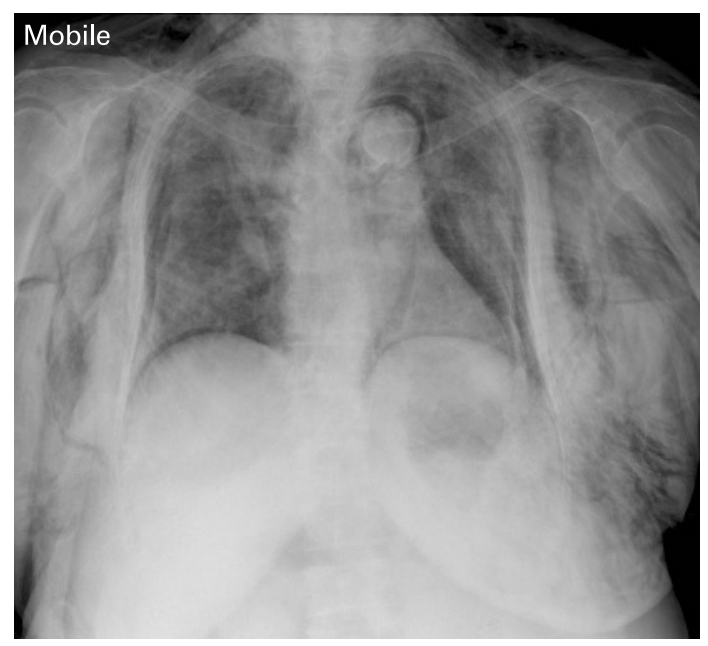

Figure 1 Post bronchoscopy radiograph at $11 \mathrm{~h}$ demonstrates extensive subcutaneous gas. Lucency outlining the aortic knuckle and left cardiac border is consistent with pneumomediastinum. There are bilateral pleural based lucencies mimicking bilateral pneumothoraces.

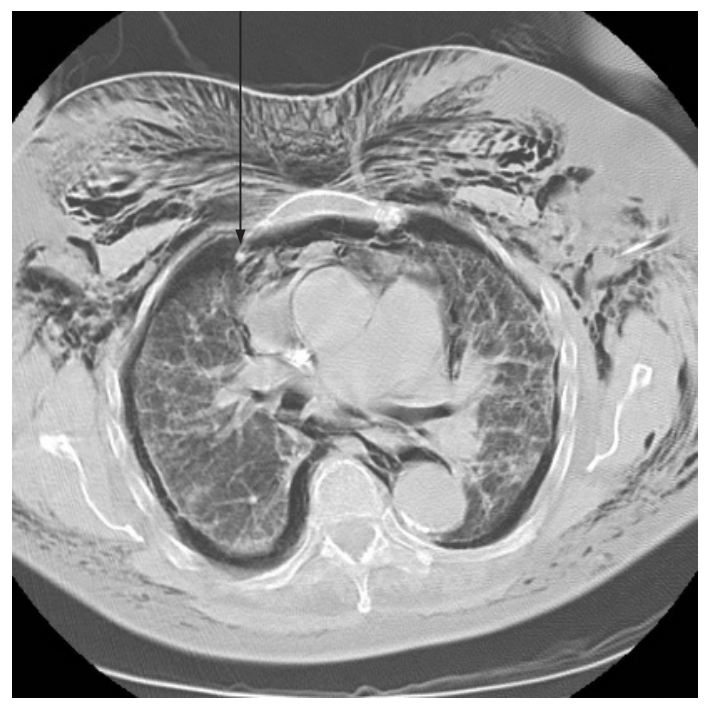

Figure 2 CT chest performed 2 days post bronchoscopy shows bilateral extrapleural air collection with right internal mammary artery traversing the collection (arrow), and multiple fibrous septae within the collection, and extensive surgical emphysema. The extrapleural air collections communicate with each other anteriorly and there is no anterior junction line identifiable.

\section{Learning points}

- Physicians caring for patients following transbronchial lung biopsy should be aware of the rare complication of bilateral extrapleural air leak mimicking pneumothoraces. ${ }^{12}$

- A communication between pleural spaces may be present in patients without a history of mediastinal surgery or sternal mediastinotomy.

Competing interests: None.

Patient consent: Obtained.

Accepted 22 January 2008

Thorax 2009;64:276. doi:10.1136/thx.2007.094375

\section{REFERENCES}

1. Findik S, Erkan L, Light RW. latrogenic bilateral pneumothorax following unilateral transbronchial lung biopsy. Br J Radiol 2006;79:e22-4.

2. Kurihara $\mathbf{Y}$, Nakajima $\mathrm{Y}$, Niimi $\mathrm{H}$, et al. Extrapleural air collections mimicking pneumothorax: helical CT finding. J Comput Assist Tomogr 1997;21:771-2. 